\section{À la table des seigneurs, des moines et des paysans du Moyen Âge}

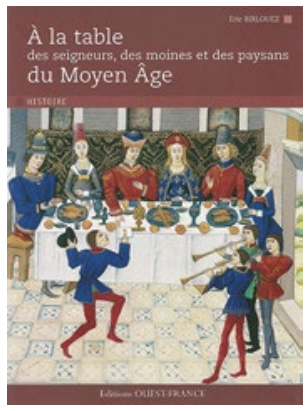

En nous invitant à découvrir l'alimentation du Moyen Âge, l'auteur nous entraîne dans un univers d'une éblouissante richesse sensorielle et symbolique. À la table des seigneurs, les plats étaient parfois colorés en jaune-orangé ou en rouge-vif. Ils étaient généreusement assaisonnés de coûteuses épices aux subtils arômes. Le festin médiéval était un spectacle " total », qui se déroulait selon un rituel très codifié et qu'agrémentaient musiciens et conteurs, jongleurs et acrobates.

Éric Birlouez nous parle aussi de la nourriture des pauvres. Il nous rappelle également que l'Église imposait, aux religieux comme aux laïcs, la stricte alternance des jours " gras " et des jours " maigres».

Le style d'alimentation du mangeur médiéval devait impérativement être conforme à son rang social. C'est pourquoi, en nous penchant sur les tables du Moyen Âge, nous en apprenons beaucoup sur la société de l'époque, sur son organisation et ses activités économiques, sur ses normes culturelles et sa symbolique.

À la table des seigneurs, des moines et des paysans du Moyen Âge, Éric Birlouez, Éditions Ouest France, 2009

\section{Festins princiers et repas paysans à la Renaissance}

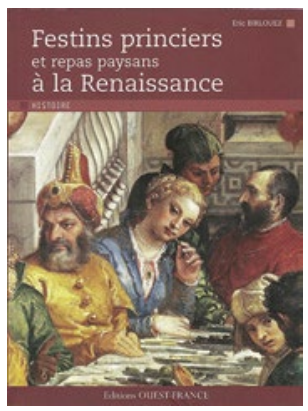

À la Renaissance, tout change... La fascination pour l'Italie, les réflexions des humanistes, l'invention de l'imprimerie, la découverte de l'Amérique, l'essor de la Réforme protestante... tous ces événements ont une influence sur les manières de manger, de cuisiner, et même de se tenir à table.

L'auteur nous parle de ces aliments (légumes, champignons, abats, beurre...) que les nobles, après les avoir longtemps méprisés, réhabilitent à l'aube du $\mathrm{XVI}^{\mathrm{e}}$ siècle. Il évoque leur goût immodéré pour la viande et les épices, ainsi que la " folie du sucre ». L'ouvrage nous apprend aussi que parmi les nouveautés "américaines ", certaines (les pommes de terre et les tomates) mettront près de trois siècles avant d'être adoptées par l'ensemble des Français. Et il nous rappelle que la Renaissance est aussi la période où apparaissent la fourchette, l'assiette et la serviette individuelle, et où se codifient les «bonnes manières de table ». Éric Birlouez nous fait également revivre ces humbles repas paysans où prédominent pain, bouillies, légumes et légumes secs.

Festins princiers et repas paysans à la Renaissance, Éric Birlouez, Éditions Ouest France, 2011
Histoire de la cuisine et de la nourriture

\author{
Du repas des cavernes \\ à la gastronomie moléculaire
}

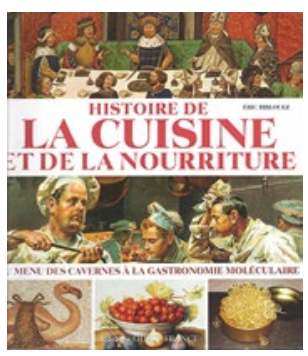

Nos lointains ancêtres de la Préhistoire étaient-ils végétariens ou avaient-ils déjà une tendance carnivore bien affirmée ? Quelles étaient les nourritures quotidiennes des pharaons, et celles des ouvriers qui bâtissaient les pyramides ? Pourquoi, entre le $\mathrm{XIV}^{\mathrm{e}}$ et le $\mathrm{XVI}^{\mathrm{e}}$ siècle, les élites européennes ont- elles été prises de passion pour les épices, puis pour le sucre et le sucré ? À quelle époque l'assiette et la fourchette ont-elles fait leur apparition sur les tables des puissants... ? C'est à la découverte d'une histoire initiée il y a 2,5 millions d'années que nous convie Éric Birlouez. L'auteur nous rappelle que les aliments consommés, ainsi que la manière dont ils sont mangés, n'ont cessé d'évoluer d'une époque à l'autre et de se différencier d'un peuple à l'autre. Car manger n'est pas seulement un acte physiologique nécessaire à la vie : c'est aussi un acte social, culturel, religieux, symbolique... et une source de plaisir.

Histoire de la cuisine et de la nourriture. Du repas des cavernes à la gastronomie moléculaire, Éric Birlouez, Éditions Ouest France, 2011

\section{À table avec les grands personnages de l'Histoire}

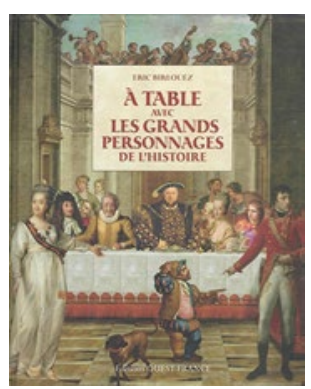

Dans ce livre fourmillant d'anecdotes et reposant sur des bases historiques sûres, nous apprenons que les Pharaons égyptiens se régalaient $\mathrm{du}$ foie (gras) des oies gavées de figues, que les Grecs pratiquaient, lors des banquets, le curieux jeu du «lancer de vin ", que le sanglier représentait à peine $1 \%$ de la quantité totale de viande qu'ingéraient les Gaulois ou encore que le légendaire appétit de Louis XIV (qui mangeait avec ses doigts !) venait du fait qu'il souffrait du ver solitaire. L'ouvrage tord également le cou à quelques légendes tenaces comme celle des pâtes que Marco Polo aurait découvertes en Chine ou celle du « tsunami gastronomique " que la florentine Catherine de Médicis aurait déclenché dans notre pays en venant y épouser le futur roi de France...

$\grave{A}$ table avec les grands personnages de l'Histoire, Éric Birlouez, Éditions Ouest France, 2012 